\title{
People Power - Computer Games in the Classroom
}

Ivan Hilliard*

Faculty of Social Sciences, Universidad Europea de Madrid, Spain

Submitted to X JIIU**: April 30, 2013 | Refereed and accepted by X JIIU: May 20, 2013

Paper presented at the X JIIU: July 11-12, 2013 | Submitted to HLRC: September 30, 2013

Editorial review: January 28, 2014 | Accepted: March 7, 2014 | Published: March 27, 2014

\begin{abstract}
This article presents a case study in the use of the computer simulation game People Power, developed by the International Center on Nonviolent Conflict. The principal objective of the activity was to offer students an opportunity to understand the dynamics of social conflicts, in a format not possible in a traditional classroom setting. Due to the game complexity, it was decided to play it in a day-long (8 hour) workshop format. A computer lab was prepared several weeks beforehand, which meant that each team of four students had access to a number of computers, being able to have the game open on several monitors at the same time, playing on one while using the others to constantly revise information as their strategy and tactics evolved. At the end of the workshop, and after handing in a group report, the 24 participants (6 groups) were asked to complete a short survey of the activity. The survey was divided into three areas: the game itself, skill development, and the workshop organization. Results showed a strong relationship between the activity and the course content, skills and competencies development, and practical know-how and leadership, as well as a strong feeling that it works well as a learning tool and is enjoyable.
\end{abstract}

Keywords: Computer games, computer simulation, workshop, edutainment, international relations

\section{Introduction}

As the great science-fiction writer Isaac Asimov (1950) once wrote "new problems, and a new series of wars". A comment on the foolishness of humanity, and its continual regression into warfare to solve problems, it also points to the uniqueness of each conflict. No two are the same, and a wide range of overlapping issues may be relevant to any analysis. These can include instrumental concepts such as resource use and distribution, corruption, and inequality; and more symbolic concepts such as group identity, feelings of relative deprivation, and historical relativism. Underlying many of these conflicts may be questions of basic human needs fulfillment, fundamentally different worldviews, and access to political power, all of which tend to make conflicts extremely complex, and seemingly intractable. Clearly, any attempt to understand such complex and intertwined issues can be greatly enhanced through experience, not always possible in the classroom.

For that reason, the subject of international conflict, which usually forms part of International Relations undergraduate degree programs, is both an interesting and complex one. As a result, in recent years students at the Universidad Europea de Madrid have worked with a computer simulation game to aid in their understanding of the field.

This paper sets out to explain how the game has been used, the advantages it offers, as well as the problems related to the introduction of what is a very different learning system. The first part of the paper discusses the advantages of computer games in the classroom, followed by an identification of problems that may arise from their use, as well as a brief breakdown of the most common types of games used in classrooms.

The second part describes one particular game and outlines how it was used in an undergraduate degree course. Then, the results of a short student survey on the game are presented, and the article finishes by analyzing how the problems and issues mentioned in the first part of the paper were dealt with.

* Corresponding author (ivanoliver.hilliard@uem.es)

** X Jornadas Internacionales de Innovación Universitaria (JIIU) [International Conference on Innovation in Higher Education], celebrated during July 11-12, 2013, Villaviciosa de Odón Campus, Universidad Europea de Madrid, Spain.

Suggested citation: Hilliard, I. O. (2014). People power - Computer games in the classroom. Higher Learning Research Communications, 4(1), 112-121. http://dx.doi.org/10.18870/hlrc.v4i1.200 


\section{Objectives}

The principal objective of this activity was to offer students an opportunity to understand the dynamics of social conflicts, in a format not possible in a traditional classroom setting. For that purpose, a workshop was set up using the computer simulation People Power, a game developed by the International Center on Nonviolent Conflict, a US-based organization. The game revolves around the management of conflict scenarios based on real-life situations, with the ultimate objective of resolving them in a nonviolent manner. Different decisions and tactics used lead to consequences which change the sociopolitical landscape as the game progresses, and the student has the opportunity to study and experience the conflict from the inside, as well as being required to analyze in depth the multiple social factors at play.

A secondary objective was to provide the opportunity to apply theoretical concepts, both in the field of conflict and conflict resolution, and demonstrate the knowledge gained during the course.

Thirdly, by working in groups where a high level of decision-making and collaborative effort were necessary (the game is highly complex and contains streams of information that needs to be constantly revised, and requires decision-making on hundreds of tactics), the activity provides ample opportunities to practice the competencies of teamwork, responsibility, decision-making, and leadership.

\section{Computer Games in the Classroom}

The use of computer games in the classroom has grown extensively in recent years, mainly due to the massive increase in their use and popularity outside the classroom, and as a result, increasing research is being conducted regarding their impact as learning tools (Kirriemuir \& McFarlane, 2003; Prensky, 2005; Rapeepisarn, Wong, Fung, \& Khine, 2006). It can be argued that computer games, like every experience in life, can serve to educate, yet questions arise as to how much can be learned, in what way, and how effectively (Egenfeldt-Nielsen, 2006).

\section{Advantages of Computer Games in the Classroom}

The popularity of computer games suggests that there may be clear gains from using them. Practically all commentators emphasize (or take for granted) the increased freedom and participation available through their use, as well as the control which the student gains over their own learning.

On a more specific level, a key advantage is that games offer a structure of rules, penalties, and objectives, meaning that while they can incorporate flexibility and decision-making on the part of the player, they also provide a type of roadmap for both teacher and student (Lee, Luchini, Michael, Norris, \& Soloway, 2004). Games can rapidly identify mistakes and miscalculations, and through a trial and error approach, enable the player to learn quickly while maintaining interest (Garcia, 2005).

A second advantage is the entertainment nature of such programs, hence the common term 'edutainment' (Garcia, 2005; Rapeepisarn et al., 2006). For example, one study by the British Education and Technology Agency (BECTA) in 2002 found that while teachers were sometimes 
frustrated by the level of non-relevant content in the games, they understood that it was useful in attracting the attention of students, being similar to the games they are accustomed to playing outside school hours (BECTA, 2002).

Generally, such design has a positive impact on the student and, as a result, can lead to improved motivation and immediate reward (Shade, 1994). Another plus is the link with the professional world. As pointed out by Floeter (2009), game-based learning is becoming increasingly common as a vehicle for company training (principally due to cost and flexibility gains, particularly in large multinational firms), so naturally the incorporation of such technologies into the educational development of future employees should be considered a positive advance.

\section{Disadvantages of Computer Games in the Classroom}

A number of issues remain to be resolved, and require further attention and research. Firstly, there are issues regarding the teacher's competencies -the capacity of each one to choose relevant games, how to effectively link the game to the academic objectives, and the correct evaluation weight to apply to the gaming activity (Williams, Boone, \& Kingsley, 2004). As a result, it may be harder to adapt them to the learning objectives due to their structured nature, highlighting the importance of choosing well.

This brings us to the second issue, regarding the quality of games. It appears that the rigorous quality control processes used by editorial companies for their "traditional" educational products (principally books) have not always been applied in the development of educational games (Shiratuddin \& Landoni, 2002; Williams, Boone, \& Kingsley, 2006). The two issues are clearly related, as the reduced emphasis on suitability at the design level often means less guidance and flexibility available to the teacher at the moment of incorporating the game into the course program.

Thirdly, partly due to the explosive growth in software games generally in society, efforts to introduce any material of such a nature may face skepticism from both students and faculty. In many ways it has been assumed that students would always react in a positive way to such a development, yet it appears that a number of conditions need to be taken into account. One of these is time constraints, due to both course and class length, where the time required to learn how to play the game or use the software may be limited, meaning that the student is immediately learning, and may not have time to master all the controls (Kirriemuir \& McFarlane, 2003). Compounding this is the fact that many students will be aware of a game's potential (it is common for games to unlock extra features as the game progresses) and may wish to continue playing, and not doing so may lead to a loss of learning momentum and create resistance to future instances where game playing is offered (Kirriemuir \& McFarlane, 2003).

Some other issues that need to be taken into account include the different skill levels among students of the same group (meaning that some may pick up the game intricacies more quickly than others); the levels of compatibility and licensing issues between the academic institution and the game producers; the quality of the school's hardware (improving graphics often require quite recent software which the school may not have or be willing/able to purchase); and the need to differentiate between learning how to use the game, and learning from using the game.

Based on the above, it could be said that the gains possibility outweighs the problems that may be faced, but that more work needs to be done. For example, there appears to be a limited 
number of studies comparing learning outcomes in the same course, where computer games were and were not used with different groups (Egenfeldt-Nielsen, 2006).

Table 1. Issues Surrounding the Use of Computer Games in the Classroom

\begin{tabular}{ll}
\hline Positive Aspects & Negative Aspects \\
\hline Providing a structured framework & Choosing right game, and effective incorporation into course \\
Entertainment value and & $\begin{array}{l}\text { Design issues, and quality control in regards to learning } \\
\text { effectiveness }\end{array}$ \\
motivational appeal & Time and space considerations \\
Link to professional level training & Legal and compatibility issues \\
\hline
\end{tabular}

\section{Types of Computer Games in the Classroom}

The study by the British Education and Technology Agency (BECTA) mentioned above identified a number of different types of computer games and hardware used in classrooms (BECTA, 2002). There was a distinction made between games with an educational emphasis, and what the authors refer to as "pure games". Generally, the pure games were used more as a reward tool for good behavior or outstanding performance (and were more likely to be available in console format), whereas the educational games were mostly simple simulations, and used in PC format.

\section{People Power - The Game of Civil Resistance}

People Power is the second generation of a game developed by a New York based company, York Zimmermann, in association with the International Center on Nonviolent Conflict. The principal objective is to teach players the skills and techniques of a non-violent resistance strategy. Each player (or group of players) is in effect the strategic coordinator behind a popular movement in conflict with an oppressive political regime. Players don't appear in the game but instead control the tactics of the different groups (and their leading members). These tactics are based on the influential teachings of the scholar Gene Sharp, considered by many to be one of the fathers of non-violent civil resistance.

The game contains a number of scenarios, each one representative of a real civil conflict where issues may include religious, ethnic, and cultural differences, competition for valuable resources, and asymmetrical political access and control. For example, one scenario appears to reflect a transition to democracy in Cuba, another is based on the struggle for equality in a theological Islamic state, and a third deals with the problems of entrenched corruption in Central Asian former Soviet states.

Within each scenario there is a detailed breakdown of the society and its key groups, including the government, police and military institutions, business, religious and media associations, political parties, student groups, and non-governmental organizations. For each of these groups, data is provided on their level of support both for the regime and the opposition, their viewpoints on key issues, the resources they control, and their influence over other groups. Each of these groups is also represented by their leading members, and there is also a mine of information available on individual skill levels and competencies, their motivational levels, and their social contacts with other groups and individuals. 
The broad outlines of the conflict are given, but it requires a substantial amount of research (inside the game) by the player to analyze and interpret the information outlined above. Players need to set specific objectives, prepare a political manifesto, and develop a strategic plan before beginning to take action. Each action (be it a meeting, a social or fund-raising event, or more direct action such as a demonstration or sit-in) requires time, money, people, and certain competencies, and will create some impact, giving instant feedback to the player. Consequences can range from loss of popular support or falling motivation by activists due to a badly planned or executed activity, through to suppression, imprisonment, and ultimately death for those involved.

The main objective is to bring individuals and groups into the opposition camp through a carefully coordinated strategy of continuous action, thus weakening government support and resolve, to the point where they are forced to concede the objectives set at the start of the game.

\section{Playing the Game}

Due to the games complexity, and also to avoid the problem of a loss of learning momentum, it was decided to play the game in a day-long (8 hour) workshop format. A computer lab was prepared several weeks beforehand, which meant that each team of four students had access to a number of computers, being able to have the game open on several monitors at the same time, playing on one while using the others to constantly revise information (individual and group resources, competencies, political affiliations, etc.) as their strategy and tactics evolved.

Based on personal experience playing, plus trails with a small number of students from an earlier course who took the game home, it was estimated that the timeframe would be sufficient to reach the objectives chosen within each scenario. There would also be enough time for those who made serious strategic errors (with the game ending quickly and unsuccessfully), to reactivate the scenario, work with the same or a slightly modified strategic plan, and use a new combination of tactics.

The date of the workshop was published in Moodle early on in the course so that students could resolve any timetabling issues, and one class of 2 hours in the days before the workshop was dedicated to learning how to use the software. The software comes with a useful tutorial on how one might play a scenario (there is a separate mini-scenario used for the tutorial), as well as a detailed glossary of what each heading means (e.g., each person has a fear level, and the higher the level the less likely they are to engage in public demonstrations of discontent with the regime, even though privately they may support the aims of the opposition).

The morning of the workshop (11am-2pm) was set aside for analysis and strategic planning, and the afternoon (3pm-8pm) for playing.

\section{Evaluation Process}

Firstly, attendance was obligatory for the 2-hour preparation class as it was felt that anyone who turned up for the workshop without understanding how to play the game would negatively impact the team's performance, due to the game's complexity and high level of decision-making required throughout the activity. It was also felt that this would reinforce the fact that the activity was a team-based one, and hence each player was also partially responsible for the learning process and evaluation grade of the others. 
This, plus a general observation of each person's behavior and attitude during the workshop by the teacher, made up $15 \%$ of the total grade. The remaining $85 \%$ of the grade was in the form of a report compiled during the activity and handed in at the end of the workshop. The report obliged each group to do a number of things:

- Demonstrate knowledge gained during the course firstly by identifying a real and ongoing conflict with similar characteristics to each of the scenarios. (This also meant they had to read the outline of each scenario before they chose which one they wanted to play). Secondly, explain in detail the conflict chosen using different theoretical concepts presented during the course (e.g., instrumental and symbolic theories of ethnic conflict, resource scarcity and resource abundance conflict theories).

- Analyze in depth the social panorama by preparing a detailed SWOT analysis for both the regime and the opposition, and then using this to write the opposition manifesto, as well as a short description of the perceived legitimacy levels of the movement they were coordinating. A related question asked them to justify the positions taken in the manifesto, which meant linkage to the SWOT analysis.

- Identify mistakes they had made and consider what they would do differently next time. In this way they were obliged to consider what they had learned playing the game.

It is important to note that the grade was in no way determined by how far into the game a team got, or how successful they were in reaching the objectives they'd set. Each member of the team received the same grade for the report, and an individual grade for the $15 \%$ related to attendance in the training session and general behavior on the day of the workshop. The activity formed part of the subject Theory and Analysis of International Conflict, and was worth $25 \%$ of the total subject evaluation.

\section{Outcomes and Student Perceptions}

At the end of the workshop, and after handing in the group report, the 24 participants ( 6 groups) were asked to complete a short survey of the activity. The survey was divided into three areas: the game itself, skill development, and the workshop organization. The results were as follows:

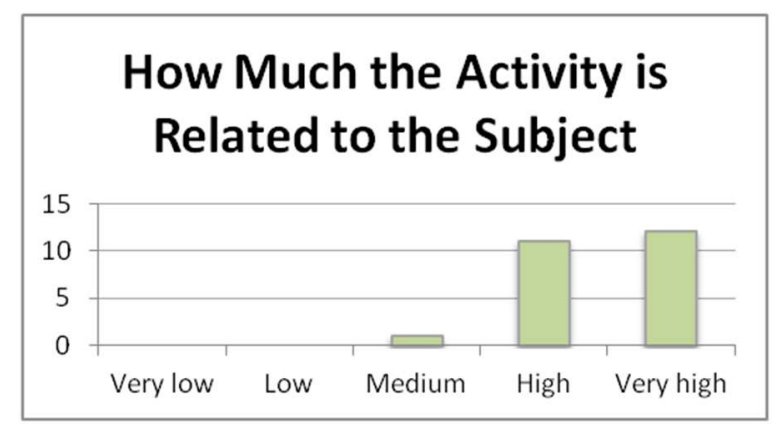

Figure 1. The game.

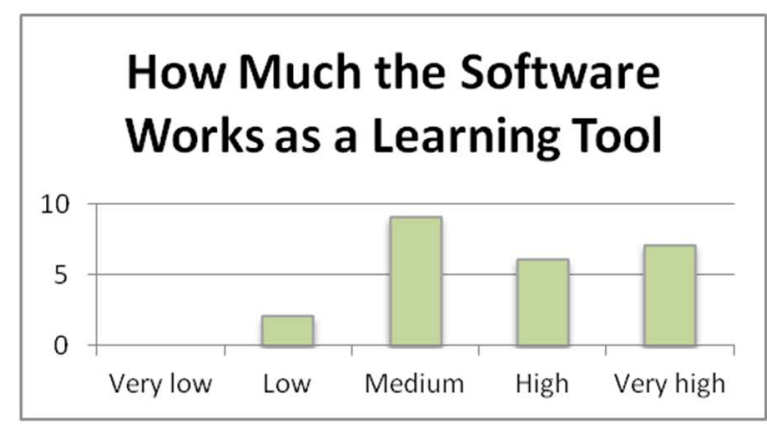

Figure 2. The game. 


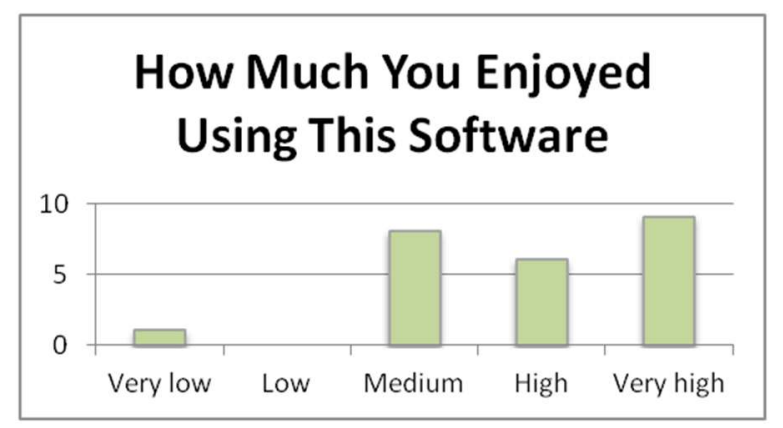

Figure 3. The game.

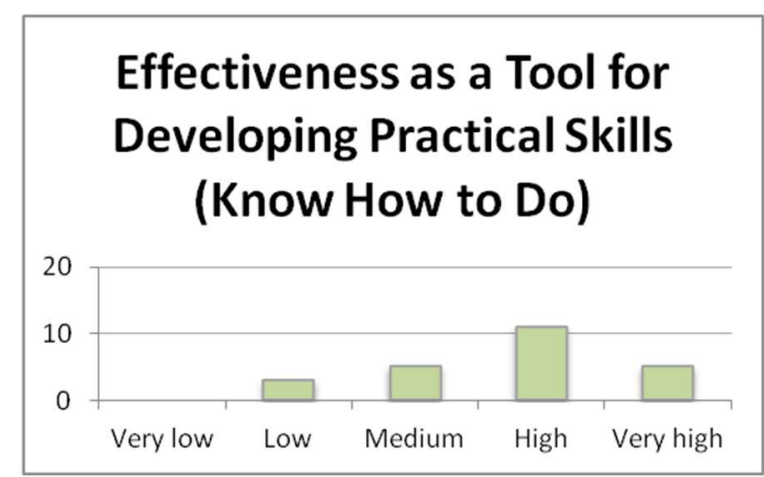

Figure 4. Skills and competencies.

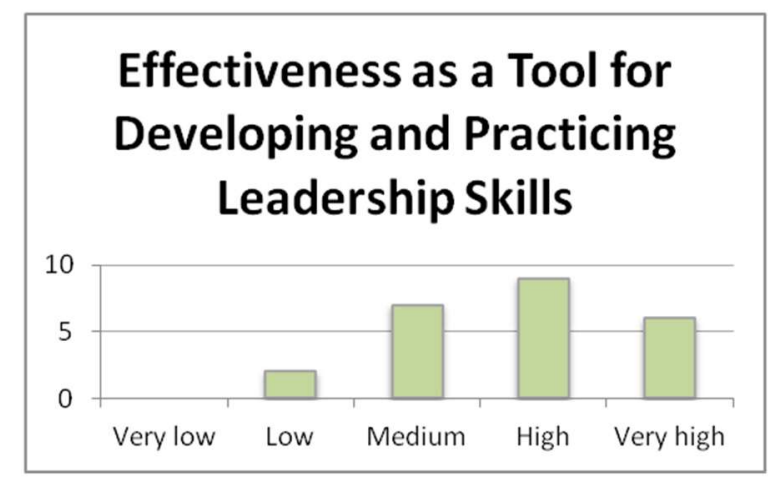

Figure 6. Skills and competencies.

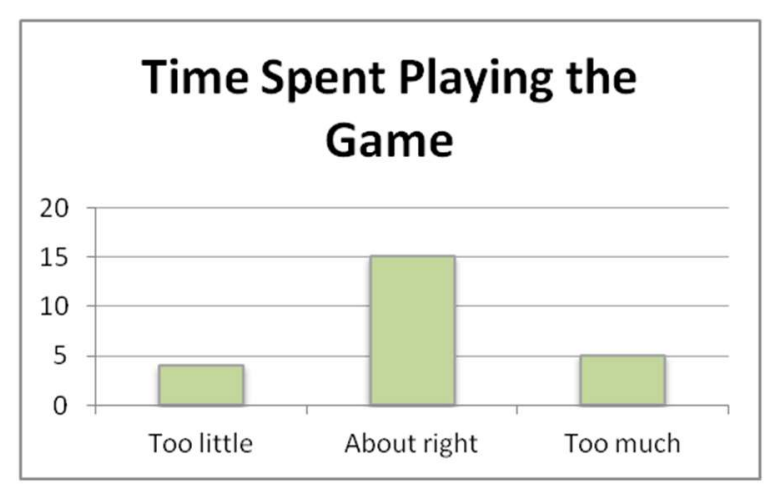

Figure 8. Organization.

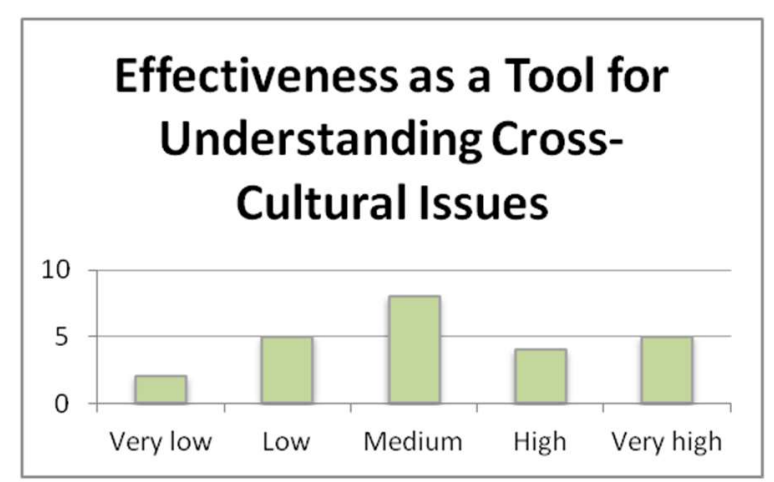

Figure 5. Skills and competencies.

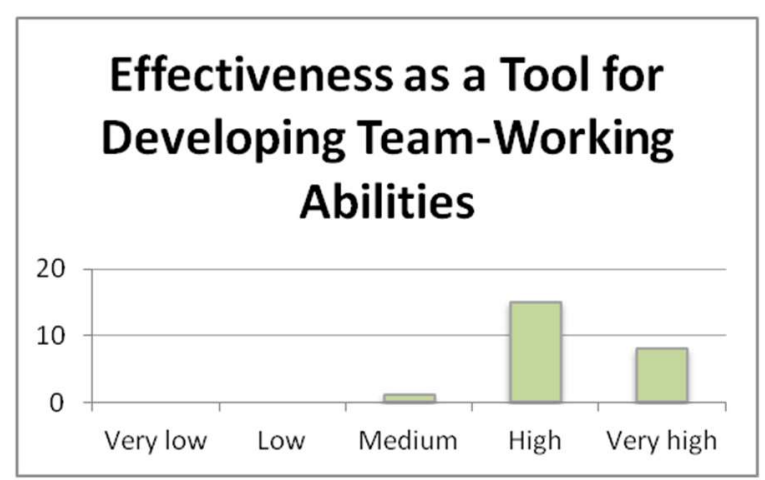

Figure 7. Skills and competencies.

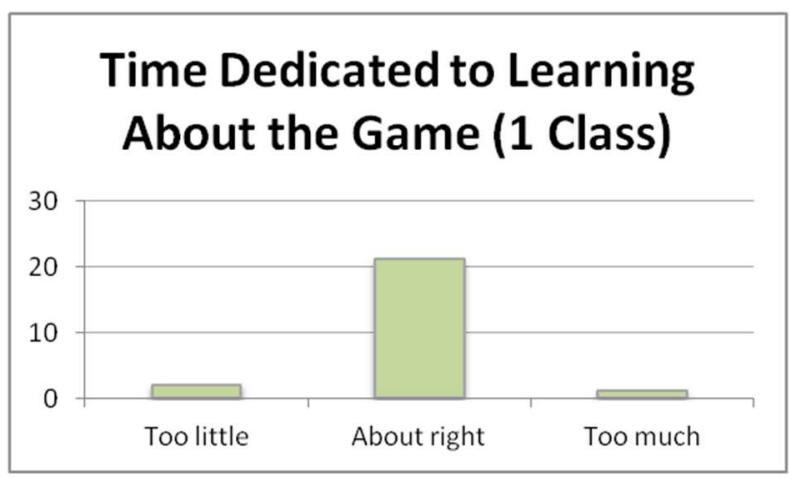

Figure 9. Organization. 


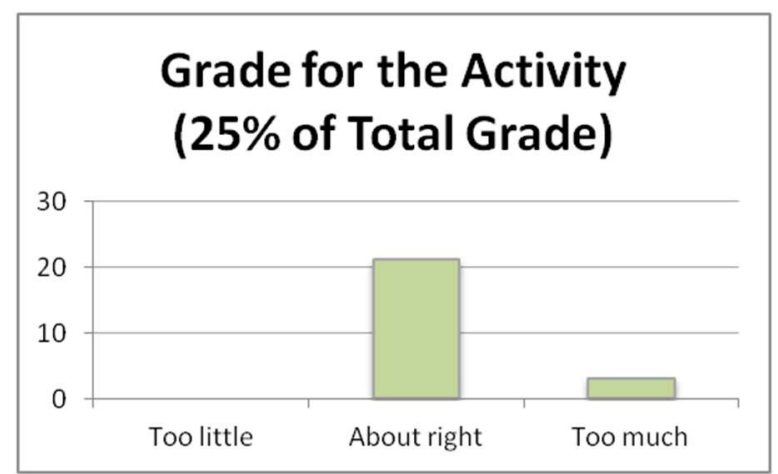

Figure 10. Organization.

There is clearly a very strong relation between the activity and the course content, as well as a strong feeling that it works well as a learning tool and is enjoyable (over $50 \%$ of responses for these two questions were high or very high). In skills and competencies development, the scores for team work are extremely positive (over $90 \%$ rated it as high or very high), and the scores for both practical know-how and leadership were good (with over $60 \%$ high or very high for both). The scores for cross-cultural understanding were more modest, perhaps due to the fact that each group, although studying all the scenarios early on in the game, spent $90 \%$ of the workshop focused on one specific one.

The organization seemed to be spot on, with both the preparation time and the weight of the activity scoring over $85 \%$ in the "about right" category. Only the length of the workshop was disputed, with about $20 \%$ preferring a shorter time frame, and about the same percentage wishing they could have played more.

\section{Conclusions}

Returning to the positive and negative issues of video games mentioned in the first section, it could be argued that the People Power workshop took advantage of the positive aspects, without suffering from the negative ones. The game contains a solid structure and requires players to prepare a political manifesto and a strategic plan, which means studying in depth the conflict parameters before beginning to play. In terms of entertainment and motivation, both the survey results and teacher observation suggest students strongly enjoyed the activity (for example, bathroom visits and breaks were kept to a minimum despite students being allowed freedom of movement due to the length of the activity). The evaluation of the activity was intentionally separated from progress in the game, which meant that the success achieved by some groups (a number of them succeeded in reaching all the objectives) was based on intrinsic motivation, rather than any desire to improve their grade.

Concerning the first of the negative points, increasingly game-makers are producing highquality games tailored to specific learning objectives. People Power has been used by the International Center on Nonviolent Conflict to train civil society groups in countries such as Tunisia and Egypt, and therefore the issue of the teacher's effectiveness in choosing a relevant game was minimal. As the game was designed by experts in the field, with the specific intention of being used as an educational tool, the design issue was not a problem either (the very high survey results for the first question reflect both these points). 
The points regarding spatial and time issues, and legal and compatibility problems, were not a problem -the game was installed on the flexible cloud laboratory of the university, MyLabs, which meant that all the students had access. Being an educational game created by a nongovernmental organization, the university was granted a license for a large number of users. Finally, the positive response in the survey to the length of the workshop, and the fact that a number of groups achieved their objectives, suggest that loss of learning motivation was not an issue.

Broadly speaking, there are four learning theories in the field of game playing, namely behaviorism, cognitivist, constructionism, and the socio-cultural approach (see Egenfeldt-Nielsen, 2006). A game such as People Power is located somewhere between the cognitivist and the constructionist approaches. (As mentioned by the author, both approaches have a lot in common). It increasingly appears that these types of games, correctly used, can provide highly effective learning experiences.

Rather than reward a certain type of behavior (not necessarily the learning objective aimed for), and focusing on extrinsic motivation, these games draw in the player and create intrinsic motivation through combining learning and the game experience itself.

From a cognitive perspective, such games challenge a player's perceived mind-frame. In the case of international conflict studies, where every social conflict is a unique set of dynamic variables, yet students will often have strong (theoretical) experience of a reduced number of conflicts (Cold War, War on Terror, Israel-Palestinian conflict), such a learning experience can be enormously useful. From a constructionist approach, the game obliges the player to interact with the material, discuss it, and use it to build knowledge. In the case of People Power, the constant debates and discussions during play revolved around the long tactics list, and the impact of each one, with the game allowing the players to see the outcomes of their discussions, in a very different format to that possible in a theoretical class.

\section{References}

Assimov, I. (1950). I, robot. New York, NY: Bantam Dell.

British Educational Communications and Technology Agency (BECTA). (2002). Curriculum software initiative: Computer Games in Education (CGE) Project. Available from http://webarchive.nationalarchives.gov.uk

Egenfeldt-Nielsen, S. (2006). Overview of research on the educational use of video games. Digital Kompetanse, 1(3), 184-213.

Floeter, A. (2009). The Effectiveness of Game-based Learning. UW-Stout Journal of Student Research, 8, 1-8. Retrieved from http://www.uwstout.edu/rs/journal-of-student-research.cfm

Garcia, G. (2005). Digital game learning. In B. Hoffman (Ed.), Encyclopedia of Educational Technology. San Diego, CA: San Diego State University, Department of Educational Technology. Retrieved from http://www.etc.edu.cn/eet/eet/

Kirriemuir, J., \& McFarlane, A. (2003). Use of computer and video games in the classroom. In Proceedings of Level Up - Digital Games Research Conference. Netherlands: Universitet Utrecht. 
Lee, J., Luchini, K., Michael, B., Norris, C., \& Soloway, E. (200I). More than just fun and games: Assessing the value of educational video games in the classroom. In E. Dykstra-Erickson \& M. Tscheligi (Eds.), CHI'04 extended abstracts on human factors in computing systems (pp. 1375-1378). New York, NY: Association for Computing Machinery (ACM).

Prensky, M. (2005). Computer games and learning: Digital game-based learning. In J. Raessens \& J. Goldstein (Eds.), Handbook of computer game studies (pp. 97-122). Cambridge, MA: MIT Press.

Rapeepisarn, K., Wong, K. W., Fung, C. C., \& Khine, M. S. (2008). The relationship between game genres, learning techniques and learning styles in educational computer games. In Z. Pan, X. Zhang, A. El Rhalibi, W. Woo, \& Y. Li (Eds.), Technologies for e-learning and digital entertainment: Proceedings of the Third International Conference: Edutainment 2008 (pp. 206-217). Berlin, Germany: Springer. http://dx.doi.org/10.1007/978-3-540-69736-7_53

Shade, D. D (1994). Computers and young children: Software types, social contexts, gender, age, and emotional responses. Journal of Computing in Childhood Education, 5(2), 177-209. (ERIC Document Reproduction Service No. EJ489942)

Shiratuddin, N., \& Landoni, M. (2002). Evaluation of content activities in children's educational software. Evaluation and Program Planning, 25(2), 175-182. http://dx.doi.org/10.1016/S01497189(02)00011-3

Williams, D. L., Boone, R., \& Kingsley, K. V. (2004). Teacher beliefs about educational software: A Delphi study. Journal of Research on Technology in Education, 36(3), 213-229. http://dx.doi.org/10.1080/15391523.2004.10782413 